\title{
Regulation of nutrient uptake and metabolism in pre-elongation ruminant embryos
}

\author{
K. D. Sinclair, J. A. Rooke and T. G. McEvoy \\ Scottish Agricultural College, Animal Biology Division, Craibstone Estate, Bucksburn, \\ Aberdeen AB21 9YA, UK
}

\begin{abstract}
Our current understanding of pre-elongation embryo metabolism and its regulation by factors both intrinsic to the embryo and present in its immediate environment is limited mainly to studies in rodents and of ruminant embryos that have been cultured in vitro. Energy metabolism in such embryos is initially low and dependent on oxidative phosphorylation for the generation of ATP. The embryo exhibits substrate preference for carboxylic acids, such as pyruvate, during this period. Glucose uptake is limited initially but increases after compaction, and it is metabolized mostly to lactate. Glucose uptake is facilitated by a number of transporters, but the presence and function of these, and their regulation by growth factors, such as insulin, are not well characterized. Even less is known about the metabolic fate of amino acids and lipids. Approximately $50 \%$ of the lipid fraction in the mature oocyte is in the form of triglyceride, much of which is oxidized during fertilization and the early cleavage stages. Immunoreactivity of the growth hormone receptor is detectable from day 3 after fertilization, and so growth hormone acting in either a paracrine or endocrine manner may serve to regulate glucose, glycogen and lipid metabolism. The metabolic and mitogenic actions of insulin and insulinlike growth factor (IGF) I and II are thought to be mediated mainly by the IGF-I receptor. The actions of leptin in the ruminant embryo are less well understood. Circulating concentrations of these growth factors, together with nutrients supplied to the follicle and oviduct, can be modified by diet, but in ways that are not fully understood. The present review discusses these issues and highlights areas for future research endeavour where emphasis is directed on to combining thoughtfully designed whole animal studies with in vitro culture experiments.
\end{abstract}

\section{Introduction}

In the first few days that follow syngamy, the mammalian zygote undergoes a complex series of biochemical and morphological changes that herald the sequential activation of the embryonic genome, required to drive the metabolic and biosynthetic pathways necessary for cell proliferation and differentiation leading to blastocyst formation. Although the nutrient 
demands of the embryo are quantitatively small during this period, they are, nevertheless, qualitatively specific and reflect the changing needs of the developing embryo in response to changing nutrient supply during its migration from the oviduct to the uterine lumen. These needs are satisfied almost entirely from exogenous nutrients available from the female reproductive tract in a manner that is carefully orchestrated by factors both intrinsic and extrinsic to the embryo (Leese, 1995).

Our current understanding of metabolism and its regulation in the pre-attachment ruminant embryo is, however, somewhat limited and is derived mainly from the study of ova from rodent and other laboratory species (Leese, 1991), and from experiments in which ruminant embryos have been cultured in a number of different in vitro systems (Watson et al., 1999; Thompson, 2000). These empirically derived and often poorly defined culture environments can support early mammalian development but in ways that sometimes lead to altered embryo metabolism and deranged genomic function. At the extreme, these effects can impart a legacy of altered conceptus development, resulting in prenatal loss and impaired neonatal health and longevity (Sinclair et al., 2000a). Limited as it may be, our knowledge of the embryotrophic effects of the oviductal environment is set to improve, with the availability of more comparative studies between the in vitro and in vivo derived embryo (for example, Niemann and Wrenzycki, 2000), and with the recent resurgence of interest in the reproductive tract as a secretory epithelium (Leese et al., 2001).

Set against this background is the need to develop a more fundamental understanding of the processes that underlie nutritionally mediated regulation of reproductive function in domestic animal species. This is particularly true of the high-yielding dairy cow, the fertility of which has declined during the last three decades (Royal et al., 2000), but is also applicable to less productive ruminant species, which may be required to adapt to nutritional constraints under increasingly extensive systems of husbandry (Sinclair and Agabriel, 1998).

\section{Pre-elongation embryo development}

\section{Energy metabolism: the early cleavage stages}

The early cleavage-stage embryo (up to 8-16 cells) has low metabolic activity (Fig. 1a), relying on oxidative phosphorylation for the generation of over $90 \%$ of ATP (Thompson et al., 1996). At this stage of development the embryo exhibits a substrate preference for carboxylic acids, such as pyruvate, to meet its energy needs (Fig. 1b). Glucose is taken up by the early embryo as indicated, for example, by the presence of transcripts for the facilitative glucose transporters Glut $-1,-3$ and -8 throughout bovine preimplantation embryo development (Augustin et al., 2001), but approximately $40 \%$ is metabolized to lactate (Fig. 1b). Glucose uptake is limited, however, under optimal oviductal and in vitro culture conditions, in which glucose concentrations are about $3 \mathrm{mmol}^{-1}$. The general consensus is that the metabolic function of glucose during this period is mainly to generate reducing equivalents (in the form of NADPH) and ribose sugars, both through the pentose phosphate pathway (PPP), and to be a source of 3-carbon precursors, all for biosynthetic purposes. Indeed, transcript expression for the glycolytic enzyme hexokinase declines as transcript expression for the Xlinked enzyme glucose-6-phosphate dehydrogenase increases between the two- and 16-cell stage in the bovine embryo (Lequarre et al., 1997), indicating a greater emphasis on the PPP during this period. Phosphofructokinase (PFK-1) is the most important control element in the glycolytic pathway, but its activity is mainly regulated after translation by the cellular ratio of ATP:ADP (Barbehenn et al., 1974). The ratio of these nucleotides is high during the early cleavage stages and, thus, may allosterically reduce the flux of glucose through this pathway. 
(a)

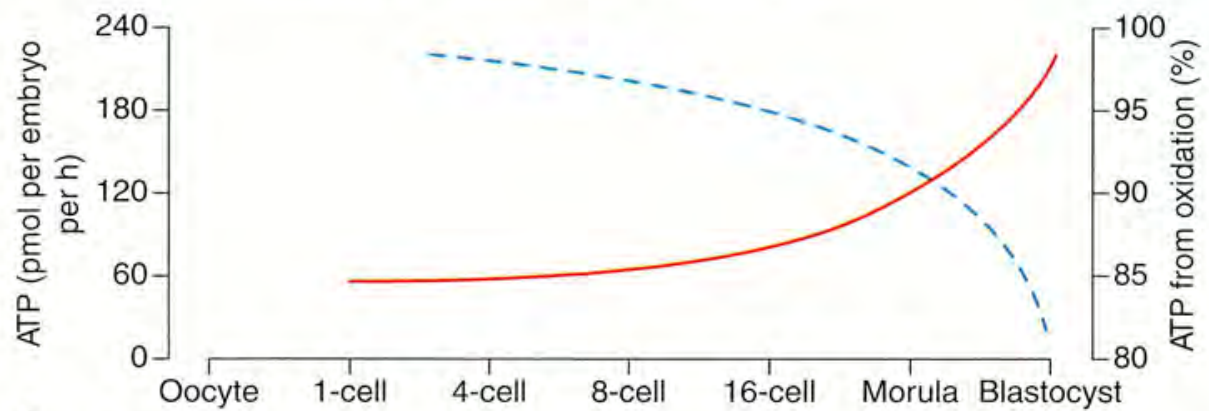

(b)

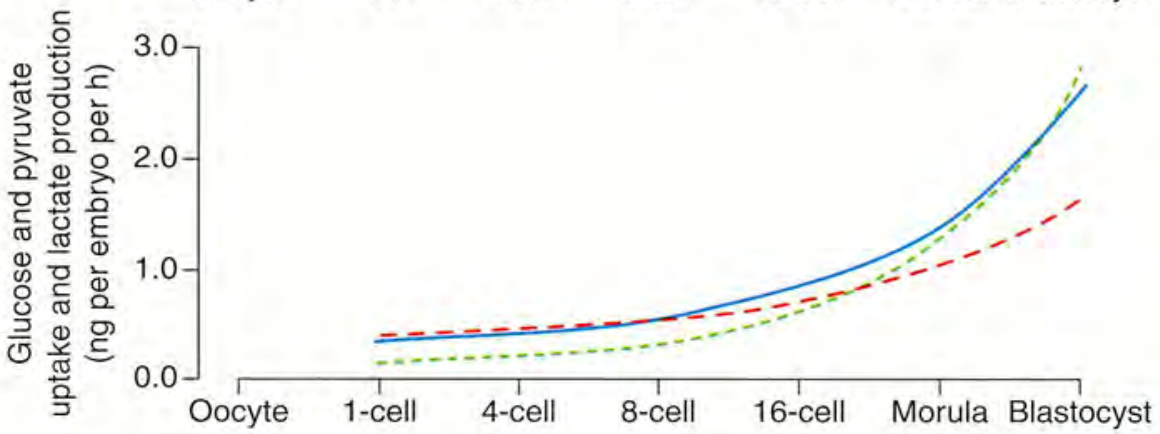

(c)

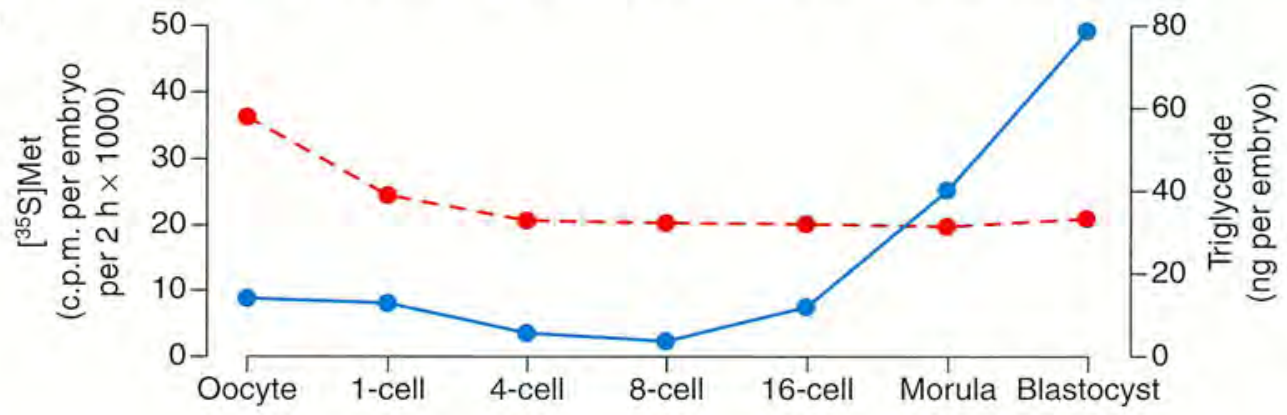

(d) Hexokinase

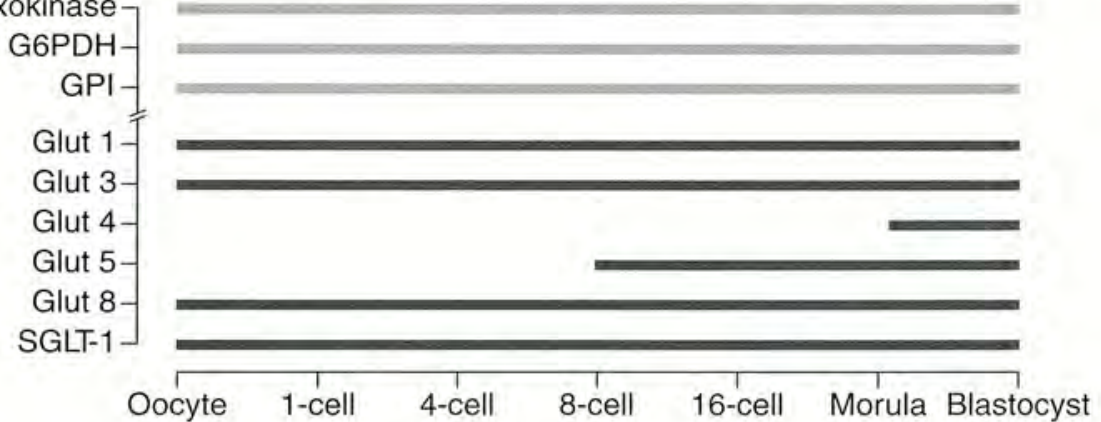

Fig. 1. Metabolic activity of the pre-elongation bovine embryo. (a) ATP production (red line) and ATP from oxidation (blue line). (b) Glucose (blue line) and pyruvate (red line) uptake, and lactate (green line) production. These data are based on that from Rieger et al. (1992) and Thompson et al. (1996, 2000). (c) Protein synthesis (blue line) and lipid composition (red line); data derived from Frei et al. (1989) and Ferguson and Leese (1999). (d) Transcript expression. G6PDH: glucose-6-phosphate dehydrogenase; GPI: glucose-phosphate-isomerase; Glut: facilitative glucose transporter; SGLT-1: sodium-dependent glucose transporter; data derived from Lequarre et al. (1997) and Augustin et al. (2001). 
Alternatively, the limiting factor may be the absence of functional facilitative glucose transporters at this stage of development.

Glutamine and threonine, two of the more abundant amino acids in the bovine oviduct (Elhassan et al., 2001), are readily taken up during the early cleavage stages in vitro (Partridge and Leese, 1996), but with little retention. Both of these amino acids act as energy substrates and probably enter the tricarboxylic acid cycle as acetyl-Coenzyme A or succinyl-Coenzyme $A$, in the case of threonine, or as $\alpha$-ketoglutarate, in the case of glutamine. As much as threequarters of glutamine may be metabolized in this way (Rieger et al., 1992). One of the products of such metabolism is alanine, derived from the transfer of an $\alpha$-amino group to pyruvate after the removal of an amido group from glutamine. Significant amounts of alanine are secreted from both in vitro cultured and in vivo derived embryos at all stages of development (Partridge and Leese, 1996), as the embryo attempts to sequester harmful ammonium ions.

In contrast to the fate of carbohydrates and amino acids, the importance of lipids as a metabolic fuel in the early pre-elongation embryo is less well understood. McEvoy et al. (2000) reported total fatty acid contents of 63 and $89 \mathrm{ng}$ in bovine and ovine oocytes, respectively, of which 23 and $25 \mathrm{ng}$ were in the form of triglycerides. Ferguson and Leese (1999) reported a $42 \%$ reduction in triglyceride content by the two-cell stage in bovine embryos. The numerous (estimated to be about 100 000; Jansen and de Boer, 1998) but structurally undifferentiated mitochondria in the mature oocyte are located centrally and in close apposition to lipid droplets (Hyttel et al., 1997). This finding indicates a role for triglyceride oxidation in ATP production during fertilization and early development, facilitated perhaps by the preferred oxidation of substrates, such as pyruvate, during this period, and regulated by pre-existing mitochondrial transcripts and proteins inherited from the oocyte.

\section{Energy metabolism: compaction and blastulation}

Compaction follows the activation of the embryonic genome (between the 8 - and 16-cell stage) and heralds the formation of the first transporting epithelium of the embryo that facilitates the development of the blastocoel. Transcripts for Glut-5 (a high-affinity fructose transporter) first appear at about this time, whereas transcripts for hexokinase increase. Glut-4 transcripts are detected shortly thereafter (Fig. 1d). Additional changes during this period include the structural and functional differentiation of mitochondria within each blastomere and their distribution between blastomeres, which can determine cell survival (Van Blerkom et al., 2000). The generation of ATP increases on a per embryo basis during pre-elongation development (Fig. 1a) although, on a cellular basis, oxidative and glycolytic activities alter little during the period after compaction (Krisher et al., 1999).

The $\beta$-oxidation of fatty acids by apposing mitochondria is thought to generate much of the water and at least some of the energy necessary for blastocoel formation (Wiley, 1987), but there is no net decrease in triglyceride content after the two-cell stage (Ferguson and Leese, 1999; Fig. 1C), indicating an uptake of lipid most probably by pinocytosis during this period. Fluid movements involved in the formation of the blastocoel are driven largely by the activity of an $\mathrm{Na}^{+} / \mathrm{K}^{+}$ATPase that increases markedly during blastulation (discussed by Leese, 1991). The energy driving this ion pump is probably derived mainly from oxidative phosphorylation and from glucose through glycolysis, and the latter pathway becomes increasingly important during the period after compaction (15-20\% of ATP solely from glycolysis, Thompson et al., 1996). In the absence of quantitative information on the oxidation of fatty acids, glucose, amino acids, such as glutamine, and carboxylic acids, such as pyruvate and lactate, are thought to be the main substrates for energy metabolism. However, lactate production accounts for nearly all glucose uptake from the morula stage onwards (Fig. 1b). Various 
hypotheses have been proposed to explain these events. Oxygen tension in the uterus is lower than in the oviduct in most mammals studied, but preparation for the anaerobic conditions associated with implantation in haemochorial placental species (discussed by Leese, 1991 ) would seem less appropriate for epitheliochorial placental species such as ruminants. It is more likely that glucose continues to contribute towards cellular biosynthesis and the production of lactate, which is thought to be involved in the maintenance of an appropriate redox equilibrium across the mitochondrial membrane (Thompson, 2000). In contrast, the metabolic fate of pyruvate may be inextricably linked to that of glutamine in attenuation of the toxic effects of hydrogen peroxide (Morales et al., 1999). In any case, high rates of glycolysis may be an artefact of in vitro culture. Although the pattern of substrate utilization and metabolism was similar for both types of embryo, lactate production was two-fold higher in in vitro produced than in vivo derived blastocysts (Khurana and Niemann, 2000). Enhanced glycolysis is a characteristic feature of cultured adult cells under stress, and may also be a feature of embryos cultured in the presence of serum, a component known to induce mitochondrial degeneration (Dorland et al., 1994).

\section{Biosynthesis}

After an initial decrease in protein content and net synthesis during the early cleavage stages, protein synthesis increases after the 16-cell stage in the bovine embryo, as indicated

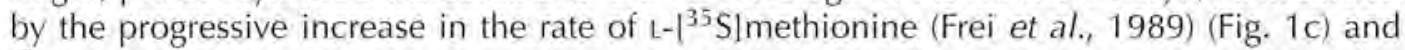
$\left[{ }^{3} \mathrm{H}\right]$ phenylalanine incorporation (Thompson et al.; 1998). These observations may be indicative of increased protein turnover or remodelling leading to de novo synthesis of proteins specified by the embryonic genome.

Essential and non-essential amino acids are found in the uterine lumen and some of these are readily taken up by in vivo derived and in vitro produced blastocysts (Partridge and Leese, 1996). Non-essential amino acids represent $63 \%$ of the total concentration of amino acids in the uterus at about day 7 (Elhassan et al., 2001), and of these, glycine, glutamate, alanine, serine and aspartate are present at higher concentrations $(12.0,4.2,3.1$, 2.7 and $1.7 \mathrm{mmol}^{-1}$, respectively). Glutamate, serine and aspartate are readily taken up by the bovine blastocyst, whereas there is a net release of glycine and alanine from the embryo, with alanine released in quantitatively important amounts. Essential amino acids are found at much lower concentrations: the most prevalent are leucine, threonine and arginine $\left(1.8,1.7\right.$ and $1.4 \mathrm{mmol}^{-1}$, respectively), but these are also readily taken up by the bovine blastocyst. The uptake of these amino acids is necessary for protein and nucleic acid synthesis, and for various other metabolic purposes, such as $\mathrm{pH}$ and osmotic regulation (Van Winkle, 2001). The relative proportions of these amino acids in the extraembryonic environment will, very likely, determine the efficiency of de novo protein synthesis tempered, to a certain extent, by the uptake of proteins by endocytosis (Thompson et al., 1998) and possibly through the recycling of ammonia nitrogen by the embryo (discussed by Leese, 1991).

From the available information it appears that the carbohydrate and lipid composition of the ruminant embryo differs markedly from that of the mouse. In contrast to the mouse, little glycogen is produced and stored in the ruminant embryo (Thompson et al., 1995), and most of the glucose taken up during the period after compaction is metabolized to lactate. The amount of lipid in the ruminant ovum is approximately 20 -fold greater than that of the mouse (76 versus $4 \mathrm{ng}$ ), and consists of approximately (\%, w/w) 50 triglyceride, 20 phospholipid, 20 cholesterol and 10 free fatty acids (McEvoy et al., 2000). These lipids consist mainly of saturated and monounsaturated fatty acids; the most abundant are palmitate $(16: 0)$, stearate 
(18:0) and oleate (18:1n-9). Polyunsaturated fatty acids comprise $<20 \%$ of total fatty acids, the most abundant being linoleate (18:2n-6).

The bovine oviduct is known to synthesize and release a variety of lipids (particularly cholesterol and phospholipids) into the oviduct and uterine lumen at concentrations that differ from that of blood serum, and at a rate that is dependent on stage of the oestrous cycle (Killian et al., 1989). The quantitative significance of this lipid compared with lipid that is derived directly from plasma has yet to be established. The ruminant embryo is known to accumulate lipids (thought to be mainly triglycerides) when cultured in the presence of serum, resulting in an increase in the number and size of intracellular lipid droplets (Thompson et al., 1995; Ferguson and Leese, 1999). The source of serum in such studies may be important in determining the degree of saturation as well as the quantity of specific fatty acids accumulated. In contrast to phospholipids, the lipophilic nature of cholesterol and fatty acids is such that their transmembrane movement into the embryo is likely to require no protein-facilitated mechanism (Hamilton, 1998). However, the extent of lipid uptake by the pre-attachment embryo in vivo is not known, and it is possible that there is significant de novo synthesis of phospholipids needed for the synthesis of cell surface and intracellular membranes (Pratt, 1980).

\section{Metabolic control}

The metabolic and biosynthetic processes discussed so far are regulated by a number of factors intrinsic to the embryo, such as enzymes, inter- and intracellular membrane transport systems and growth factors, in concert with a number of factors extrinsic to the embryo, that function in either a paracrine or endocrine manner (Fig. 2). Transcripts for some of these factors are present within the follicle-enclosed oocyte and can be detected at various stages of pre-elongation development (Fig. 1d), but are also found in the epithelia of both the oviduct and uterus (for example see Stevenson and Wathes, 1996). Attempts have been made to quantify the relative abundance of some of these transcripts in ruminant embryos (for example, Lequarre et al., 1997; Yaseen et al., 2001), but the functionality of many awaits further investigation.

\section{Growth hormone}

Growth hormone receptor (GHR) mRNA has been detected in oocytes from pre-antral and antral follicles in both cattle and sheep (Eckery et al., 1997; Kölle et al., 1998), and in bovine embryos during the early pre-attachment period (Kölle et al., 2001). Addition of growth hormone to maturation and culture media improves cleavage rates and the proportion of bovine embryos that develop to the blastocyst stage (Moreira et al., 2002). However, although GHR transcripts are present in the germinal vesicle stage oocyte, GHR immunoreactivity is detectable only from day 3 (fertilization = day 0) (Kölle et al., 2001), confirming earlier observations that the stimulatory effect of growth hormone on maturation of bovine oocytes is probably mediated by receptors present in cumulus cells (Izadyar et al., 1997). Transcript expression for GHR increases from day 2 to day 6 and is associated with GHR immunoreactivity in both the cytoplasm and nucleus of the pre-attachment bovine embryo (Kölle et al., 2001) (Fig. 2). The appearance of growth hormone transcripts from about day 8 is indicative of an autocrineparacrine role for this $32 \mathrm{kDa}$ protein but also indicates that the maternally derived growth hormone is key to receptor activation during the early pre-elongation period. The means by which growth hormone alters embryo metabolism are not clear. Growth hormone mediates the depletion of glycogen and lipid reserves in day 8 blastocysts in a manner that enhances 


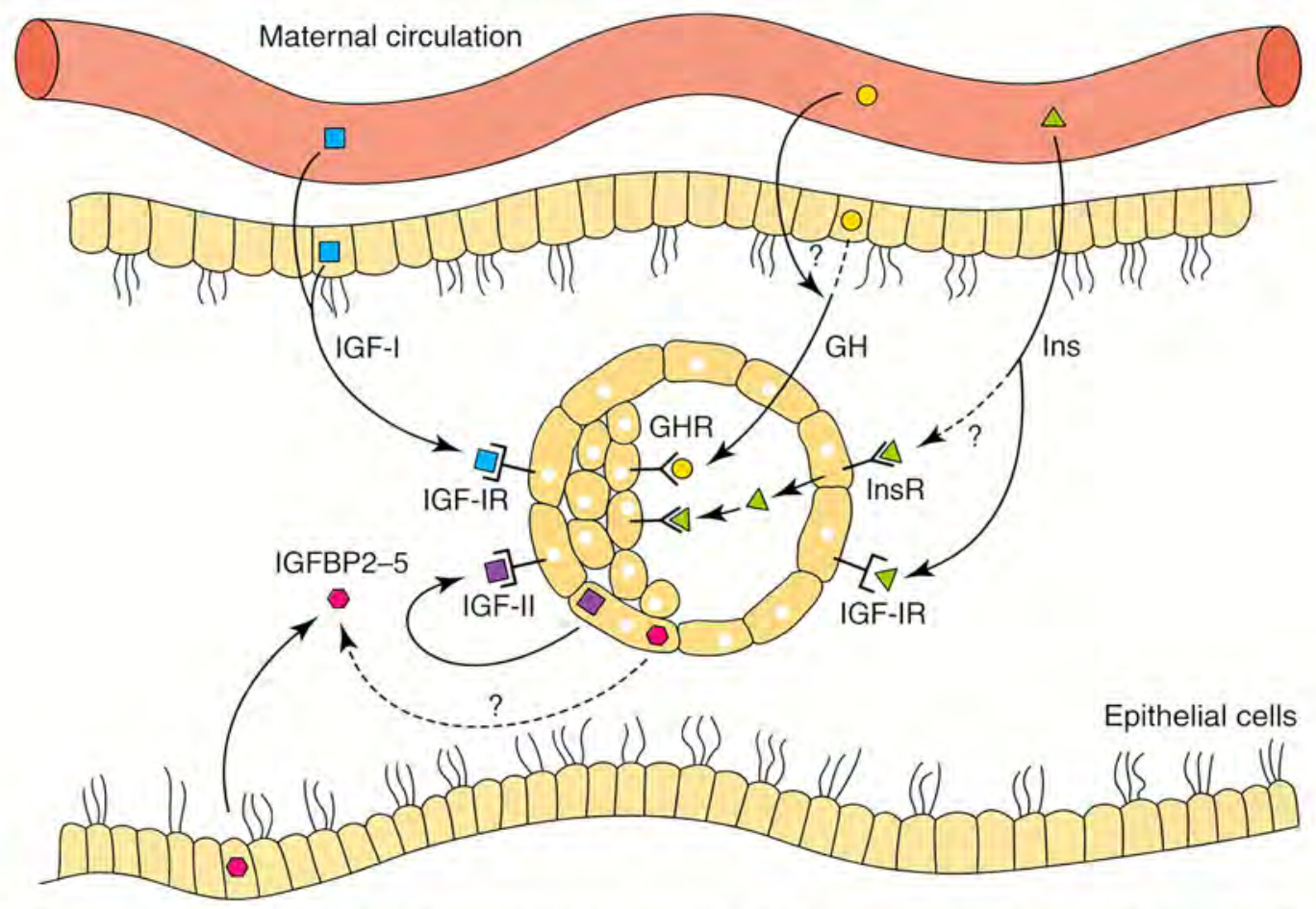

Fig. 2. Growth factor mediated regulation of early embryo development in ruminants. Transcripts for insulin (Ins) are not present in the pre-attachment embryo and surrounding reproductive tissues, indicating a truly endocrine role for this pancreatic growth factor. Similarly, transcripts for growth hormone $(\mathrm{GH})$ are not present in the bovine embryo before the blastocyst stage. In contrast, $\mathrm{GH}$ receptor (GHR) immunoreactivity has been detected from day 3 onwards in bovine embryos and is located in the nucleus and cytoplasm of blastomeres within the inner cell mass. Transcripts for the insulin receptor (InsR) are present at all stages of pre-implantation development, but functional receptors may be absent. Both insulin and insulin-like growth factor I (IGF-I) are thought to mediate their actions mainly through the IGF-I receptor (IGF-IR). Controversy also surrounds the presence of transcripts for IGF-I, indicating a paracrine or endocrine role in regulating early embryo development. In contrast, transcripts for IGF-II are present throughout pre-elongation development and both autocrine and paracrine roles have been suggested, with mitogenic actions mediated by either the InsR or IGF-IR. The actions of IGF-I and -11 are moderated by a number of IGF-binding proteins (IGFBP2-5) present in the reproductive tract.

embryo viability (Kölle et al., 2001). In so doing, growth hormone may serve to maintain substrate supply during periods of shortage, thereby reducing the incidence of programmed cell death within the embryo (Kölle et al., 2002). In contrast, during periods of plenty, while at physiological concentrations that are typical of those observed in well-fed animals, growth hormone may serve to increase glucose uptake and protein synthesis, in an insulin-like manner (Pantaleon et al., 1997). These apparently opposite effects may be due to differences in intracellular signalling pathways (discussed later).

\section{Leptin}

Leptin is the $16 \mathrm{kDa}$ cytokine product of the obese gene $(o b)$ and through the long form of its receptor is known to activate the Janus kinase signal transducers and activators of transcription (Jak-Stat) pathway (Baumann et al., 1996). Functional receptors for leptin are 
present in bovine thecal and granulosa cells (Spicer and Francisco, 1997), and are also present in metaphase II (MII) mouse oocytes (Matsuoka et al., 1999). Leptin protein has been further immunolocalized to MII human oocytes (Cioffi et al., 1997) and to mouse and human morulae where it is co-expressed with Stat3 (Antczak and Van Blerkom, 1997). Leptin influences many aspects of reproductive function, but a direct role for this protein in ruminant gamete and early embryo development remains to be elucidated.

\section{Insulin-like growth factors and binding proteins}

Transcripts for IGF-II, IGF-IR, IGF-IIR and insulin-like growth factor binding proteins (IGFBP)-2, -3 and -4 are detectable in the oocyte and throughout pre-elongation development in ruminant embryos (for a review, see Watson et al., 1999). However, evidence for the presence of transcripts for IGF-I in the bovine embryo is less conclusive (Watson et al., 1992; Yaseen et al., 2001); transcripts for IGFBP-5 are detectable only from the blastocyst stage (Winger et al., 1997). Consequently, each of these factors, with the possible exception of IGF-I, may act in an autocrine manner to regulate cell proliferation and embryo metabolism (Fig. 2). However, it should be noted that targeted gene-deletion studies for some IGF family members in mice have indicated a degree of redundancy in the IGF system during the early pre-implantation period, leading some authors (Watson et al., 1999) to comment on the 'autonomous nature' of early development. Nevertheless, ruminant embryos in culture are responsive to IGF peptides (Prelle et al., 2001).

Compelling evidence now exists to indicate that IGF-IIR is not involved in signal transduction but targets IGF-II and mannose-6-phosphate tagged ligands to lysosomes for degradation (Poretsky et al., 1999). It seems that the metabolic and mitogenic activities of IGF-II are mediated by either the IGF-IR or the insulin receptor (InsR), two heterotetrameric transmembrane receptors with tyrosine kinase activity that share a high degree of sequence similarity. Despite the structural similarities between insulin and IGF-I, binding to their cognate receptors tends to be specific. Likewise, despite similarities in structure and sequence homology between IGF-IR and InsR, important differences in their structure and function mean that, for most types of cell, InsR is more effective in mediating metabolic responses, whereas the IGF-IR is primarily involved in mitogenesis and cell survival (Dupont and LeRoith, 2001).

There is controversy about whether bovine follicles express mRNA encoding IGF-I (Spicer et al., 1993; Armstrong et al., 2000). Given the uncertainty over IGF-I production by the oocyte (discussed earlier) it seems that the primary source of this growth factor during oocyte and early embryo development must be from extrafollicular sites. When added to culture medium both IGF-I and IGF-II promote oocyte maturation in cattle and pigs, an effect mediated most probably by a cAMP-protein kinase A dependent pathway (Sirotkin et al., 1998). The addition of IGF-I to culture medium has also been shown to result in modest improvements in blastocyst yields and in the number of cells, with fewer apoptotic cells (Prelle et al., 2001). The actions of IGF-I and -11 are moderated by a number of binding proteins through cell association in a manner determined by the presence of specific multivalent cations such as zinc (McCusker, 1998). Thus, IGFBPs serve both to enhance and delay the activity of IGF-I and -II.

\section{Insulin}

Transcripts encoding insulin have not been detected in murine, bovine or ovine preattachment embryos or in surrounding reproductive tissues, indicating a truly endocrine role for this pancreatic growth factor. In contrast to the mouse embryo, functional studies 
with this hormone in ruminant embryos are limited to a few in vitro culture experiments, which have demonstrated a positive effect on blastocyst development and on the number of cells when insulin is added to simple serum-free media, particularly in the presence of amino acids (Matsui et al., 1995). Transcripts for InsR are detectable in the oocyte and throughout pre-elongation development in the ruminant embryo (Watson et al., 1992) (Fig. 2). However, in the mouse blastocyst, the insulin- and IGF-I-stimulated uptake of glucose is mediated via the IGF-I receptor and may be independent of signalling through insulin receptor substrate 1 (IRS-1) (Pantaleon and Kaye, 1996). The significance of this finding is not understood but may be a peculiar feature of the mouse embryo which does not express the insulin-regulated glucose transporter, Glut-4, during pre-implantation development and expresses only the other known insulin-regulated transporter, Glut-8, from the blastocyst stage (Carayannopoulos et al., 2000), where it may be critical for embryo survival (Pinto et al., 2002). It is, therefore, doubtful that insulin regulates glucose uptake before the blastocyst stage in mice and, therefore, may function as a growth factor during the early cleavage stages possibly via the IGF-IR. In contrast, transcripts for Glut- 8 are present throughout preattachment development in the bovine embryo, with transcripts for Glut-4 appearing from the blastocyst stage (Fig. Id); therefore insulin may have a role in regulating glucose uptake during early pre-attachment development in this species. However, the function of the InsR in the bovine embryo is unclear, for the anti-IGF-I receptor antibody (alpha IR-3) has been found to block the insulin and IGF-I mediated stimulation of embryo development completely in this species (Matsui et al., 1997).

\section{Regulated metabolism}

On receptor binding, growth hormone has been shown to cause tyrosine phosphorylation of two insulin-responsive docking proteins (IRS-1 and -2), and with insulin and IGF-1, to share common signalling pathways involved in gene regulation and cellular metabolism (Fig. 3). Direct crosstalk between the leptin and insulin-signalling systems has also been demonstrated in a hepatoma cell line, whereby leptin was found to increase tyrosine phosphorylation and phosphatidylinositol-3 kinase (PI-3 K) binding to IRS-1 (Szanto and Kahn, 2000). Consequently, a common range of cellular responses may be mediated by these factors subsequent to binding to their cognate receptors. These responses may include the regulation of glucose metabolism through the translocation of Glut- 4 and -8 to the plasma membrane, the allosteric control of PFK-1 via PFK-2 regulated production of fructose 2,6 bisphosphate, and the synthesis of glycogen through the phosphorylation and hence inactivation of glycogen synthase kinase 3 (GSK3). The pro-survival $\mathrm{Bcl} 2$ family proteins are thought to help cells adapt to a lower rate of metabolism brought about by growth factor withdrawal or limited glucose availability (Plas and Thompson, 2002). However, it should be recognized that details of these pathways in the early mammalian embryo remain to be determined, and that the outcome of crosstalk between the different intracellular signalling pathways will be influenced by substrate availability as well as the allosteric regulation of enzyme action. Additional levels of control may be mediated at the extracellular level, within the follicular compartment and oviductal environment, through interactions between the various growth factors, their receptors and binding proteins (Fig. 2). For example, bovine oviductal cells are known to synthesize and release IGF-I and -1I polypeptides as well as IGFBP-2,-4 and -5 (Winger et al., 1997), and blastocyst expression of transcripts for IGFBP-2 and -5 increases after IGF-I treatment (Prelle et al., 2001). Furthermore, at least within the follicular compartment, metabolic hormones, such as insulin and glucagon, are known to regulate IGFBP production (Chamberlain and Spicer, 2001). 


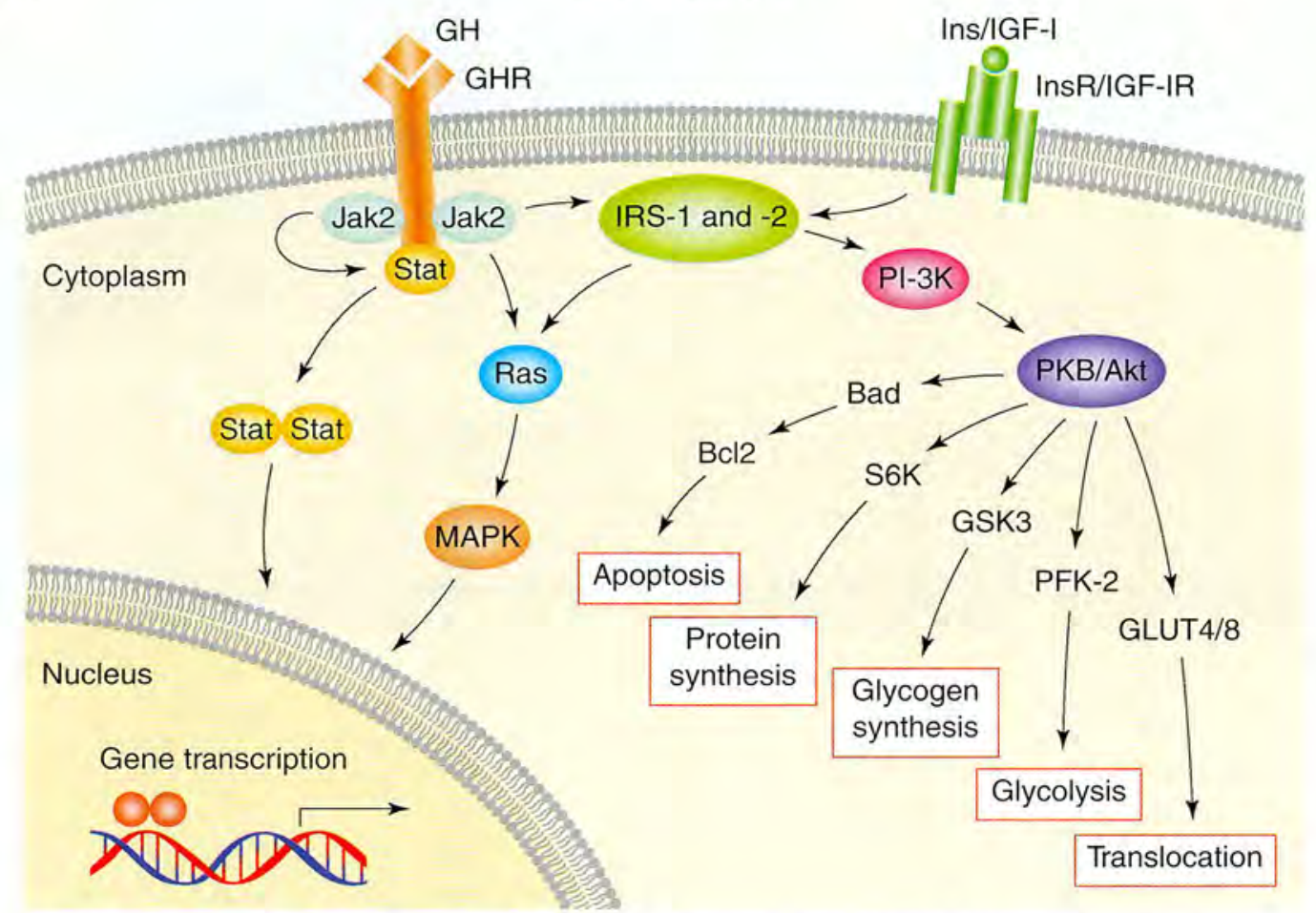

Fig. 3. Possible common signalling pathways for growth hormone $(\mathrm{GH})$, insulin (I) and insulinlike growth factor I (IGF-I) in the regulation of gene expression and cellular metabolism in the pre-elongation ruminant embryo. Cellular processes regulated through the phosphatidylinositol-3 kinase (PI-3K) and protein kinase B (PKB/Akt) pathways include survival, protein synthesis and glucose metabolism. Jak, Janus kinase; Stat, signal transducers and activators of transcription; Ras, a GTP-binding switch protein; MAPK, mitogen-activated protein kinase; Bad and $\mathrm{Bcl}-2$ are pro- and anti-apoptotic members of the Bcl-2 family; S6K, S6 kinase; GSK3, glycogen synthase kinase 3; PFK-2, 6-phosphofructo-2-kinase; IRS-1 and -2: insulin receptor substrate 1 and 2.

\section{Animal nutrition and pre-elongation embryo development}

The discussion thus far has focused on nutrient metabolism and its regulation in the preelongation embryo. In addition to altering nutrient supply to growing ovarian follicles and the uterine tract, dietary manipulations will alter the systemic concentrations of key metabolic and reproductive hormones, all of which may impinge directly or indirectly on the pre-elongation embryo. However, our current understanding of these interactive processes is poor.

\section{Energy metabolism}

In the absence of micronutrient imbalances, moderate undernutrition in non-lactating ruminants seldom has any detrimental effect on oocyte or early embryo development. In contrast, overfeeding can compromise both oocyte maturation and early embryo viability. For example, in non-lactating heifers, high dietary intake increases ovarian follicular growth but has a detrimental effect on the potential of oocytes (particularly those from small follicles) to develop to the blastocyst stage after in vitro maturation, fertilization and culture (Armstrong et al., 2001). Similarly, ad libitum feeding of high starch diets reduces blastocyst yield and quality after superovulation in cattle (Yaakub et al., 1999). In the study of 
Armstrong et al. (2001), high dietary energy intakes were associated with increased insulin and IGF-I concentrations in peripheral circulation and reduced steady state concentrations of mRNA encoding IGFBP-2 and -4 , and IGF-IR and InsR in small follicles. A precedent for the latter observation has been established in the mouse, in which exposure of preimplantation embryos to high concentrations of IGF-I and insulin result in the downregulation of the IGF-IR, and an increase in apoptosis and resorption rates after transfer (Pinto et al., 2002). These effects are mediated, at least in part, by a reduction in the insulin-stimulated uptake of glucose. The situation may be exacerbated in the insulin-resistant over-fat animal, but links between insulin resistance and ovarian disorders in ruminants have yet to be established (Opsomer et al., 1999). Hyperglycaemia increases Bax-mediated apoptosis within the inner cell mass of the mouse embryo, paradoxically, through a downregulation of facilitative glucose transporters and intra-embryonic hypoglycaemia (Moley, 2001). In ruminants, the feeding of high starch diets is more likely to result in sub-clinical acidosis, a consequence of the excessive production of lactate from rapidly fermented carbohydrates within the rumen. The resulting decrease in blood $\mathrm{pH}$ may correspond to reduced uterine $\mathrm{pH}$ and result in impaired embryo development. Intracellular $\mathrm{pH}$ is regulated by the $\mathrm{Na}^{+} / \mathrm{H}^{+}$antiporter and the $\mathrm{HCO}_{3}-\mathrm{Cl}^{-}$exchanger, but neither seem to function very well in the bovine embryo during the early cleavage stages (Lane and Bavister, 1999), indicating a certain vulnerability of the pre-attachment embryo to changes in the oviductal environment. Finally, high starch diets may also lead to deranged embryo metabolism, with increased expression of transcripts for the antioxidant enzyme $\mathrm{Cu} / \mathrm{Zn}$-superoxide dismutase detected in blastocysts when the amount of barley fed to heifers was increased (Wrenzycki et al., 2000).

\section{Protein metabolism}

High protein diets are offered to dairy cows to support milk production, but the feeding of such diets is often associated with impaired reproductive function (Butler, 1998). Reproductive problems are exacerbated when these diets contain high amounts of ruminally degradable protein, particularly when offered to animals in negative energy balance (Papadopoulos et al., 2001). Such feeding practices result in increased plasma concentrations of ammonium, urea and progesterone, and decreased plasma concentrations of insulin (Sinclair et al., 2000b). Plasma urea concentrations are inversely related to uterine $\mathrm{pH}$ (Elrod and Butler, 1993), and so may challenge the pre-elongation embryo that is ill equipped to control intracellular $\mathrm{pH}$. In heifers, high plasma concentrations of ammonium and urea during both the preantral and antral stages of follicular development are associated with reduced cleavage rates after in vitro maturation and fertilization, and reduced blastocyst production rates after in vitro culture (Sinclair et al., 2000c,d). Both glucose and protein (uptake of $\left.{ }^{35} \mathrm{~S}\right]$ methionine) metabolism were increased in surviving embryos in those studies, as in the study of McEvoy et al. (1997). These observations may be indicative of metabolic stress, on the part of surviving embryos, perhaps as a consequence of altered intracellular $\mathrm{pH}$ (Ruddock et al., 2000) or impaired genomic function. The latter effect, in addition to compromising embryo survival, also impinges on subsequent fetal development and, consequently, the health and viability of offspring (Sinclair et al., 2000a).

\section{Conclusions}

At present, our understanding of the metabolic and biosynthetic processes within the preelongation ruminant embryo and their regulation by factors both intrinsic to the embryo and present within the uterus is rather limited. The preceding discussion highlights important 
gaps in our knowledge, and points to areas of future research endeavour. For example, our understanding of substrate uptake and metabolism is limited mainly to embryos produced in vitro, but recent studies with in vivo derived embryos have begun to redress this limitation. Transcripts for a number of developmentally important genes have been identified during pre-elongation development, but the translation and functional significance of many of these remain to be determined. Pertinent to the present discussion are factors that regulate nutrient uptake and cellular metabolism. The limited amount of available information on these factors pertains mostly to the mouse and, of the ruminant species, to cows. Little is known about their intracellular signalling pathways and crosstalk between these pathways. Many of these factors act in a paracrine or endocrine manner and so can be influenced by the physiological and nutritional state of the dam. Again, Jittle is known about how whole animal nutrition, acting through these factors, influences early embryo development. Such information will be gleaned only by combining thoughtfully designed whole animal studies with in vitro culture experiments.

Scottish Agricultural College receives financial support from the Scottish Executive, Environment and Rural Affairs Department, and the Department for Environment, Food and Rural Affairs.

\section{References}

Antczak M and Van Blerkom J (T997) Oocyte influences on early development; the regulatory proteins leptin and STAT3 are polarized in mouse and human oocytes and differentially distributed within the cells of the preimplantation stage embryo Molecular Human Reproduction 3 1067-1086

Armstrong DG, Gutierrez CG, Baxter G, Glazyrin AL, Mann GE, Woad KJ, Hogg CO and Webb R (2000) Expression of mRNA encoding IGF-I, IGF-II and type 1 IGF receptor in bovine ovarian follicles Journal of Endocrinology 165 101-113

Armstrong DG, McEvoy TG, Baxter G, Robinson JJ, Hogg CO, Woad KJ, Webb R and Sinclair KD (2001) The effect of dietary energy and protein on bovine follicular dynamics and embryo production in vitro: associations with the ovarian insulin-like growth factor system Biology of Reproduction 641624 1632

Augustin R, Pocar P, Navarrete-Santos A, Wrenzycki C, Gandolfi F, Niemann $\mathrm{H}$ and Fischer B (2001) Glucose transporter expression is developmentally regulated in in vitro-derived bovine preimplantation embryos Molecular Reproduction and Development 60370 376

Barbehenn EK, Wales RG and Lowry OH (1974) Regulation of oxidative phosphorylation in the mammalian cell Proceedings National Academy of Sciences 71 1056-1060

Baumann $H$, Morella KK, White DW, Demski $M$, Bailon PS, Kim H, Lai CF and Tartagalia LA (1996) The full-length leptin receptor has signalling capabilities of interleukin 6-type cytokine receptors Proceedings National Academy of Sciences USA 93 8374-8378

Butler WR (1998) Review: effect of protein nutrition on ovarian and uterine physiology in dairy cattle Journal of Dairy Science 81 2533-2539

Carayannopoulos MO, Chi MM-Y, Cui $Y$, Pingsterhaus JM, McKnight RA, Mueckler M, Devaskar SU and Moley KH (2000) GLUT8 is a glucose transporter responsible for insulin-stimulated glucose uptake in the blastocyst Proceedings National Academy of Sciences USA $977313-7318$

Chamberlain CS and Spicer LJ (2001) Hormonal control of ovarian cell production of insulin-like growth factor binding proteins Molecular and Cellutar Endocrinology 182 69-81

Cioffi JA, Van Blerkom J, Antczak M, Shafer A, Wittmer S and Snodgrass HR (1997) The expression of leptin and its receptors in pre-ovulatory human follicles Molecular Human Reproduction 3 467-472

Dorland M, Gardner DK and Trounson AO (1994) Serum in synthetic oviduct fluid medium causes mitochondrial degeneration in ovine embryos Journal of Reproduction and Fertility Abstract Series $\mathbf{1 3} 70$

Dupont J and LeRoith D (2001) Insulin and insulin-like growth factor 1 receptors: similarities and differences in signal transduclion Hormone Research 55 Supplement 2 22-26

Eckery DC, Moeller CL, Nett TM and Sawyer HR (1997) Localization and quantification of binding sites for follicle-stimulating hormone, luteinizing hormone, growth hormone and insulin-like growth factor I in sheep ovarian follicles Biology of Reproduction 57 507-513

Elhassan YM, Wu G, Leanez AC, Tasca RJ, Watson AJ and Westhusin ME (2001) Amino acid concentrations in fluids from the bovine oviduct and uterus and in KSOM-based culture media Theriogenology $551907-1918$ 
Elrod CC and Butler WR (1993) Reduction in fertility and alteration in uterine $\mathrm{pH}$ in heifers fed excess ruminally degradable protein Journal of Animal Science 71 694-701

Ferguson EM and Leese HJ (1999) Triglyceride content of bovine oocytes and early embryos Journal of Reproduction and Fertility 116 373-378

Frei RE, Schultz GA and Church RB (1989) Qualitative and quantitative changes in protein synthesis occur at the 8-16 cell stage of embryogenesis in the cow Journal of Reproduction and Fertility 86 637-641

Hamilton IA (1998) Fatty acid transport: difficult or easy? Journal of Lipid Research 39 467-481

Hyttel P, Fair T, Callesen H and Greve T (1997) Oocyte growth, capacitation and final maturation in cattle Theriogenology 47 23-32

Izadyar F, Van Tol HT, Colenbrander B and Bevers MM (1997) Stimulatory effect of growth hormone on in vitro maturation of bovine oocytes is exerted through cumulus cells and not mediated by IGF-1 Molecular Reproduction and Development 47 175-180

Jansen RPS and de Boer K (1998) The bottleneck: mitochondrial imperatives in oogenesis and ovarian follicular fate Molecular and Cellular Endocrinology $14581-88$

Khurana NK and Niemann H (2000) Energy metabolism in preimplantation bovine embryos derived in vitro or in vivo. Biology of Reproduction 62 847-856

Killian GJ, Chapman DA, Kavanaugh IF, Deaver DR and Wiggin HB (1989) Changes in phospholipids, cholesterol and protein content of oviduct fluid of cows during the aestrous cycle Journal of Reproduction and Fertility $86 \quad 419-426$

Kölle S, Sinowatz F, Boie G and Lincoln D (1998) Developmental changes in the expression of the growth hormone receptor messenger ribonucleic acid and protein in the bovine ovary Biology of Reproduction $59836-842$

Kölle S, Stojkovic M, Prelle K, Waters M, Wolf E and Sinowatz F (2001) Growth hormone $(\mathrm{GH}) / \mathrm{GH}$ receptor expression and $\mathrm{GH}$-mediated effects during early bovine embryogenesis Biology of Reproduction 64 1826-1834

Kölle S, Stojkovic M, Boie G, Wolf E and Sinowatz F (2002) Growth hormone inhibits apoptosis in in vitro produced bovine embryos Molecular Reproduction and Development 61 180-186

Krisher RL, Lane M and Bavister BD (1999) Developmental competence and metabolism of bovine embryos cultured in semi-defined and defined culture media Biology of Reproduction 60 1345-1352

Lane M and Bavister BD (1999) Regulation of intracellular $\mathrm{pH}$ in bovine oocytes and cleavage stage embryos Molecular Reproduction and Development 54 396401

Leese HJ (1991) Metabolism of the preimplantation mammalian embryo. In Oxford Reviews of Reproductive Biology 13 35-72
Leese HJ (1995) Metabolic control during preimplantation mammalian development Human Reproduction Updale 1 63-72

Leese HJ, Tay II, Reischl J and Downing SJ (2001) Formation of Fallopian tubal fluid: role of a neglected epithelium Reproduction 121 339-346

Lequarre AS, Grisart B, Moreau B, Schuurbiers N, Massip A and Dessy F (1997) Glucose metabolism during bovine preimplantation development: analysis of gene expression in single oocytes and embryos Molecular Reproduction and Development 48216-226

McCusker RH (1998) Controlling insulin-like growth factor activity and the modulation of insulin-like growth factor binding protein and receptor binding Journal of Dairy Science 81 1790-1800

McEvoy TG, Robinson JJ, Aitken RP, Findlay PA and Robertson IS (1997) Dietary excesses of urea influence the viability and metabolism of preimplantation sheep embryos and may affect fetal growth among survivors Animal Reproduction Science 47 71-90

McEvoy TG, Coull GD, Broadbent PJ, Hutchinson JSM and Speake BK (2000) Fatty acid composition of lipids in immature cattle, pig and sheep oocytes with intact zona pellucida Journal of Reproduction and Fertility $118163-170$

Matsui $\mathbf{M}$, Takahashi $Y$, Hishinuma $\mathbf{M}$ and Kanagawa $\mathbf{H}$ (1995) Stimulatory effects of insulin on the development of bovine embryos fertilized in vitro, Journal of Veterinary Medical Science 57 331-336

Matsui $M$, Takahashi $Y$, Hishinuma $M$ and Kanagawa $\mathbf{H}$ (1997) Stimulation of the development of bovine embryos by insulin and insulin-like growth factor-1 (IGF-1) is mediated through the IGF-I receptor Theriogenology 48 605-616

Matsuoka T, Tahara M, Yokoi T, Masumoto N, Takeda T, Yamaguchi M, Tasaka K, Kurachi $\mathrm{H}$ and Murata $\mathrm{Y}$ (1999) Tyrosine phosphorylation of STAT3 by leptin through leptin receptor in mouse metaphase 3 stage oocyte Biochemical and Biophysical Research Communications $256480-484$

Moley KH (2001) Hyperglycaemia and apoptosis: mechanisms for congenital malformations and pregnancy loss in diabetic women Trends in Endocrinology and Metabolism $1278-82$

Morales H, Tilquin P, Rees JF, Massip A, Dessy F and Van Langendonckt A (1999) Pyruvate prevents peroxideinduced injury of in vitro preimplantation bovine embryos Molecular Reproduction and Development 52 149-157

Moreira F, Paula-Lopes FF, Hansen PJ, Badinga L and Thatcher WW (2002) Effects of growth hormone and insulin-like growth factor-1 on development of in vitro derived bovine embryos Theriogenology 57 895-907

Niemann $\mathbf{H}$ and Wrenzycki $\mathbf{C}(2000)$ Alterations of expression of developmentally important genes in preimplantation bovine embryos by in vitro culture 
conditions: implications for subsequent development Theriogenology 53 21-34

Opsomer G, Wensing Th, Laevens $\mathrm{H}$, Coryn $\mathrm{M}$ and de Kruif A (1999) Insulin resistance: the link between metabolic disorders and cystic ovarian disease in high yielding dairy cows Animal Reproduction Science $56211-222$

Pantaleon M and Kaye PL (1996) IGF-I and insulin regulate glucose transport in mouse blastocysts via IGF-I receptor Molecular Reproduction and Development $4471-76$

Pantaleon M, Whiteside EJ, Harvey MB, Barnard RT, Waters MJ and Kaye PL (1997) Functional growth hormone $(\mathrm{GH})$ receptors and $\mathrm{GH}$ are expressed by preimplantation mouse embryos: a role for $\mathrm{GH}$ in early embryogenesis? Proceedings National Academy of Sciences $945125-5130$

Papadopoulos S, Lonergan P, Gath V, Quinn KM, Evans ACO, O'Callaghan D and Boland MP (2001) Effect of diet quantity and urea supplementation on oocyte and embryo development in sheep Theriogenology 55 1059-1069

Partridge RJ and Leese HJ (1996) Consumption of amino acids by bovine preimplantation embryos Reproduction, Fertility and Development 8 945-950

Pinto AB, Schlein AL and Moley KH (2002) Preimplantation exposure to high insulin-like growth factor I concentrations results in increased resorption rates in vivo. Human Reproduction 17 457-462

Plas DR and Thompson CB (2002) Cell metabolism in the regulation of programmed cell death Trends in Endocrinology and Metabolism 13 74-78

Poretsky L, Cataldo NA, Rosenwaks Z and Giudice LC (1999) The insulin-related ovarian regulatory system in health and disease Endocrine Reviews 20 535-582

Pratt HPM (1980) Phospholipid synthesis in the preimplantation mouse embryo Journal of Reproduction and Fertility $58237-248$

Prelle K, Stojkovic M, Boxhammer K, Motlik J, Ewald D, Arnold G) and Wolf E (2001) Insulin-like growth factor I (IGF-I) and long R R IGF-I differently affect development and messenger ribonucleic acid abundance for IGF-binding proteins and type I IGF receptors in in vitro produced bovine embryos Endocrinology 142 1309-1316

Rieger D, Loskutoff M and Betteridge KJ (1992) Developmentally related changes in the uptake and metabolism of glucose, glutamine and pyruvate by cattle embryos produced in vitro. Reproduction, Fertility and Development 4 547-557

Royal MD, Darwash AO, Flint APF, Webb R, Woolliams JA and Lamming GE (2000) Declining fertility in dairy cattle: changes in traditional and endocrine parameters of fertility Animal Science 70 487-501

Ruddock NT, Machaty Z and Prather RS (2000) Intracellular $\mathrm{pH}$ increase accompanies parthenogenetic activation of porcine, bovine and murine oocytes
Reproduction, Fertility and Development 12 201207

Sinclair KD and Agabriel J (1998) The adaptation of domestic ruminants to environmental constraints under extensive conditions Annales de Zootechnie $47347-353$

Sinclair KD, Young LE, Wilmut $\mathrm{I}$ and McEvoy TG (2000a) In utero overgrowth in ruminants following embryo culture: lessons from mice and a warning to men Human Reproduction 15 Supplement 5 $68-86$

Sinclair KD, Sinclair LA and Robinson JJ (2000b) Nitrogen metabolism and fertility in cattle. I. Adaptive changes in intake and metabolism to diets differing in their rate of energy and nitrogen release in the rumen Journal of Animal Science 78 2659-2660

Sinclair KD, Kuran M, Staines ME, Aubailly S, Mackie K, Robinson J], Webb R and McEvoy TG (2000c) In vitro blastocyst production following exposure of heifers to excess rumen degradable nitrogen during either the pre-antral or antral stages of follicular growth Journal of Reproduction and Fertility Abstract Series. 2541

Sinclair KD, Kuran M, Gebbie FE, Webb R and McEvoy TG (2000d) Nitrogen metabolism and fertility in cattle. II. Development of oocytes recovered from beifers offered diets differing in their rate of nitrogen release in the rumen fournal of Animal Science 78 2670-2680

Sirotkin AV, Taradjnik TE, Makarevich AV and Bulla J (1998) Effect of follicular cells, IGF-I and tyrosine kinase blockers on oocyte maturation Animal Reproduclion Science 51 333-344

Spicer LJ and Françisco CC (1997) The adipose obese gene product, leptin: evidence of a direct inhibitory role in ovarian function Endocrinology 1383374 3379

Spicer LJ, Alpizar E and Echternkamp SE (1993) Effects of insulin, insulin-like growth factor I, and gonadotrophins on bovine granulosa cell proliferation, progesterone production, estradiol production, and (or) insulin-like growth factor I production in vitro. Journal of Animal Science 71 1232-1241

Stevenson KR and Wathes DC (1996) Insulin-like growth factors and their binding proteins in the ovine oviduct during the oestrous cycle Journal of Reproduction and Fertility $10831-40$

Szanto I and Kahn CR (2000) Selective interaction between leptin and insulin signalling pathways in a hepatic cell line Proceedings National Academy of Sciences USA 97 2355-2360

Thompson JG (2000) In vitro culture and embryo metabolism of cattle and sheep embryos - a decade of achievement Animal Reproduction Science 60-61 263-275

Thompson JG, Bell ACS and Tervit HR (1995) Partitioning of glucose carbon in post-compaction ovine embryos Animal Reproduction Science 38 119-126 
Thompson JG, Partridge RJ, Houghton FD, Cox Cl and Leese HI (1996) Oxygen uptake and carbohydrate metabolism by in vitro derived bovine embryos Journal of Reproduction and Fertility 106 299-306

Thompson IG, Sherman ANM, Allen NW, McGowan LT and Tervit HR (1998) Total protein content and protein synthesis within pre-elongation stage bovine embryos Molecular Reproduction and Development $50 \quad 139-145$

Van Blerkom J, Davis P and Alexander S (2000) Differential mitochondrial distribution in human pronuclear embryos leads to disproportionate inheritance between blastomeres: relationship to microtubular organization, ATP content and competence Human Reproduction $152621-2633$

Van Winkle LJ (2001) Ámino acid transport regulation and early embryo development Biology of Reproduclion 64 1-12

Watson A], Hogan A, Hahnel A, Wiemer KE and Schultz GA (1992) Expression of growth factor ligand and receptor genes in the preimplantation bovine embryo Molecular Reproduction and Development 31 87-95

Watson AJ, Westhusin ME and Winger QA (1999) IGF paracrine and autocrine interactions between conceptus and oviduct Journal of Reproduction and Fertility 54 303-315

Wiley LM (1987) Development of the blastocyst: role of cell polarity in cavitation and cell differentiation. In The Mammalian Preimplantation Embryo: Regulalion of Growth and Differentiation In Vitro pp 65-93 Ed. BD Bavister. Plenum Press, New York

Winger QA, de los Rios P, Han VKM, Armstrong DT, Hill DJ and Watson Al (1997) Bovine oviductal and embryonic insulin-like growth factor binding proteins: possible regulators of 'embryotrophic' insulinlike growth factor circuits Biology of Reproduction 56 1415-1423

Wrenzycki C, De Sousa P, Overström EW, Duby RT, Hermann D, Watson AJ, Niemann $\mathrm{H}, \mathrm{O}^{\prime}$ Callaghan D and Boland MP (2000) Effects of superovulated heifer diet type and quantity on relative mRNA abundances and pyruvate metabolism in recovered embryos fournal of Reproduction and Fertility $\mathbf{1 1 8}$ $69-78$

Yaakub H, O'Callaghan D and Boland MP (1999) Effect of type and quantity of concentrates on superovulation and embryo yield in beef heifers Theriogenology 51 1259-1266

Yaseen MA, Wrenzycki C, Herrmann D, Carnwath JW and Niemann $H$ (2001) Changes in the relative abundance of mRNA transcripts for insulin-like growth factor (IGF-I and IGF-II) ligands and their receptors (IGF-IR/IGF-IIR) in preimplantation bovine embryos derived from different in vitro systems Reproduction $122601-610$ 